\title{
Thunbergia Laurifolia Lind. Extract Alleviates Motor Impairments in Acute MPTP Mouse Model of Parkinson's Disease
}

Thanasit Chaiwut ${ }^{1}$, Pornarez Thaweekhotr ${ }^{1}$, Chanida Thongsopha ${ }^{1}$, Noppadol Phasukdee ${ }^{1}$, Sumitra Gomonchareonsiri ${ }^{2}$, Nitaya Boontim ${ }^{3}$, Napuskorn Sanpow ${ }^{4}$, Chainarong Tocharus ${ }^{1}$, and Ranida Quiggins ${ }^{1 *}$

\author{
${ }^{1}$ Department of Anatomy, Faculty of Medicine, Chiang Mai University, \\ Chiang Mai 50200, Thailand \\ ${ }^{2}$ Department of Physiology, Faculty of Medicine, Chiang Mai University, \\ Chiang Mai 50200, Thailand \\ ${ }^{3}$ Science and Technology Research Institute, Chiang Mai University, Chiang Mai \\ 50200, Thailand \\ ${ }^{4}$ Northern Neuroscience Center, Faculty of Medicine, Chiang Mai University, \\ Chiang Mai 50200, Thailand
}

*Corresponding author.E-mail: ranida.quiggins@cmu.ac.th https://doi.org/10.12982/CMUJNS.2020.0030

Received: June 7, 2019

Revised: September 6, 2019 Accepted: September 20, 2019

\begin{abstract}
Parkinson's disease (PD) is a neurodegenerative disease whereby there is the characteristic progressive degeneration of dopaminergic neurons in the substantia nigra pars compacta (SNpc) leading to motor deficiencies. The 1-methyl-4-phenyl-1, 2, 3, 6-tetrahydropyridine (MPTP), is the neurotoxin that was used to induce the mice to be models of PD. Thunbergia laurifolia Lindl. (TL) is a Thai herbal medicine which is used for reducing the effects of toxins. This study aims to find out whether TL leaf extract can prevent the onset of PD motor impairments due to MPTP by using pre TL and post TL treatments and observing the mouse's latency times on the Rotarod test, the frequency of movements on the Motor Activity Test, and the numbers of the dopaminergic neurons on the tyrosine hydroxylase immunoreaction $\left(\mathrm{THir}^{+}\right)$The results showed that the latency times and motor activity of the pre TL treated group were significantly higher than that of the pre-vehicle treated group at $P<0.01$. On the other hand, there was no difference between those of the post TL and the post vehicle treated groups. The number of THir ${ }^{+}$neurons of pre TL and post TL treated groups were significantly higher than that of their vehicle
\end{abstract}


treated groups, yet the number of the pre TL treated group was less different $(P<0.05)$ than that of the post $T L$ treated group $(P<0.01)$ when compared with the control. In conclusion, we have determined that the pre-treatment of TL extract in the MPTP mouse model of PD alleviates motor impairments.

Keywords: Thunbergia Laurifolia Lind., Motor impairments, Parkinson's disease, Dopaminergic neurons

\section{INTRODUCTION}

Parkinson's Disease (PD) is a chronic progressive neurodegenerative disorder that occurs when there is a dopaminergic neuronal loss in the substantia nigra pars compacta (SNpc). It is characterized by motor abnormalities including tremors, muscular rigidity, bradykinesia, and postural abnormalities (Jankovic, 2008). The most common toxin which is used for inducing PD in animal models is 1-methyl-4-phenyl-1,2,3,6-tetrahydropyridine (MPTP) (Philippens et al., 2010; Tieu, 2011; Blandini and Armentero, 2012; Kasahara et al., 2013). This toxin endangers the dopaminergic neurons in the SNpc leading to dopaminergic neurotransmitter synthesis loss occurrences that are found in PD. It was found that the dopaminergic neurons in SNpc in PD had decreased which is indicated by the presence of immunoreactive tyrosine hydroxylase $\left(\mathrm{THir}^{+}\right.$) cells (Kozina et al., 2014; Alam et al., 2017). The motor function and behavior of animals with PD are accessed by Rotarod and Motor Activity Tests which are found to be significantly different from those of normal animals (Hutter-Saunders et al., 2012).

Thunbergia laurifolia Lindl. (TL) or "Rang chuet" is known as a Thai herb medicinal plant which is well known for its detoxification qualities. $T L$ is used to treat poisonings that can occur from insecticides, arsenic, alcohol, chemicals, drugs, food, and water (Junsi and Siripongvutilorn, 2016). Usanawarong et al. (2000) indicated that aqueous $T L$ leaf extract can reduce toxicity in paraquat intoxicated rats. Tangpong and Satarug (2010) also found that TL leaf extract attenuated the neuronal degeneration in the hippocampus and restored memory loss of lead intoxicated rats. Not only is it used detoxify poisons, $T L$ also has several pharmacological properties being an anti-inflammatory, an anti-oxidant, an anti-microbial, and an anti-nociceptive agent (Chan et al., 2011; Boonyarikpunchai et al., 2014). Thongsaard and Marsden (2013) found that TL extract increased extracellular dopamine levels in striatum.

The acute MPTP mouse model of PD was induced by intraperitoneal injections (i.p.) of MPTP at $20 \mathrm{mg} / \mathrm{kg}$ of body weight (BW), 4 times every 2 hours, as has been done in previous study (Lee et al., 2017). This model of PD represents the earliest phase of PD which is indicated by having $53 \%$ of the dopaminergic neurons compared to that of a normal subject (Pain et al., 2013), and having a $40 \%$ to $90 \%$ deficiency in dopamine neurotransmitters (Jackson- 
Lewis and Przedborski 2007). The acute model of PD has been used to study the neuroprotective effects and properties for improving motor abnormalities using 'Jitai Tablet', a traditional Chinese medicine (Liu et al., 2014) and "Combretum leprosum mart", a Brazilian medicinal plant (Moraes et al., 2016). However, these properties have not yet been studied using Thai medicinal plants such as 'Rang chuet'. We hypothesize that the $T L$ extract could prevent the occurrence of Parkinson's disease in mouse induced by MPTP. We investigated whether TL extract is a protective agent for attenuating the motor dysfunction and neuronal degeneration in the MPTP mouse model of PD.

\section{MATERIALS AND METHODS}

\section{Preparation of Thunbergia laurifolia Lindl. (TL) leaves extracts}

Fresh $T L$ leaves were harvested from an area in Sing Buri Province, Thailand. Its dried form was collected as a voucher specimen (QBG. No. 104862) and was stored at Queen Sirikit Botanic Garden Herbarium (QBG), Ministry of Natural Resources and Environment, using the scientific name that was identified at Ethnobotany and Northern Thai Flora Laboratory, Department of Biology, Faculty of Science, Chiang Mai University. The fresh $T L$ leaves were thoroughly washed and dried in a hot-air oven at $40-50{ }^{\circ} \mathrm{C}$ for $2-3$ days, or until the leaves had completely dried. The dried leaves were ground into a fine powder. The powder was extracted with absolute ethanol. The container of the extract solution was put into a shaker set at slow speed for 4 hours every 4 days. The crude $T L$ extract solution was filtered using Whatman No. 1 filter paper. The sample of the $T L$ extract solution was analyzed for the total anti-oxidant agents as $106.0 \mathrm{mg} / \mathrm{L}$ and total phenolic compounds $290.59 \mu \mathrm{g} / \mathrm{ml}$ by the Research Laboratory for Analytical Instrument and Electrochemical (AIE). The final solution of the $T L$ extract was dried in a rotary evaporator (Heidolph model. MX07R-20-HD2E, USA), and then was lyophilized in a freeze dryer. The dried $T L$ extract was diluted with Tween 80 solution before being used as a dilution of $200 \mathrm{mg} / \mathrm{kg}$ of BW. The rest of dried $T L$ extract was stored at $-20{ }^{\circ} \mathrm{C}$.

\section{Animal and experiment protocol}

A total of 30 male C57BL/6 mice (Nomura Siam International, Thailand), aged 5 weeks weighing between 20-25 g., were used. All mice were caged in controlled conditions having a cycle of 12 hours of darkness and 12 hours of light with temperature set at $25{ }^{\circ} \mathrm{C}$. They were allowed free access to food and water. The study protocol was approved by the Animal Ethics Committee of the Faculty of Medicine, Chiang Mai University (Approved Protocol No. 26/2560).

The mice were randomly divided into 5 groups $(n=6)$ : (1) control group; mice received saline via an IP injection, (2) MPTP + pre Tween 80 group; mice received Tween 80 as a "vehicle" before the MPTP injection (3) MPTP + pre $T L$ group; mice received $T L$ extract before the MPTP injection, (4) MPTP + post 
Tween 80 group; mice received Tween 80 after MPTP injection and (5) MPTP + post $T L$ group; mice received $T L$ extract after the MPTP injection.

Mice in this study were induced to be the acute model of PD on day 8 of the experimental period of 15 days by the IP injections of the MPTP at $20 \mathrm{mg} / \mathrm{kg}$ of BW, 4 times every 2 hours as done by Lee (2017). For the pre-treatment strategy, the i.p. injection of $T L$ extract with a dilution of $200 \mathrm{mg} / \mathrm{kg}$ of body weight and Tween 80 of the same volume were given to the mice for one week (day 1-7) before the MPTP injection. For post treatment strategy, the $T L$ extract and Tween 80 were given to mice for 1 week (day 8-14) after the last dose of the MPTP inducing (Figure 1). All mice were tested for their motor co-ordination and motor movement using the Rotarod Test and Motor Activity monitor or the Open Field Test, respectively. The latency times on the rotarod and the motor activity, or frequency of movement were recorded at day 0 , day 7 (one day before the MPTP IP injection), day 9 (one day after the MPTP IP injection), and day 15 (one week after the MPTP IP injection). All mice were sacrificed on the following day and their brains were extracted. Immunofluorescence analysis was then performed to review the number of $\mathrm{THir}^{+}$neurons in SNpc.

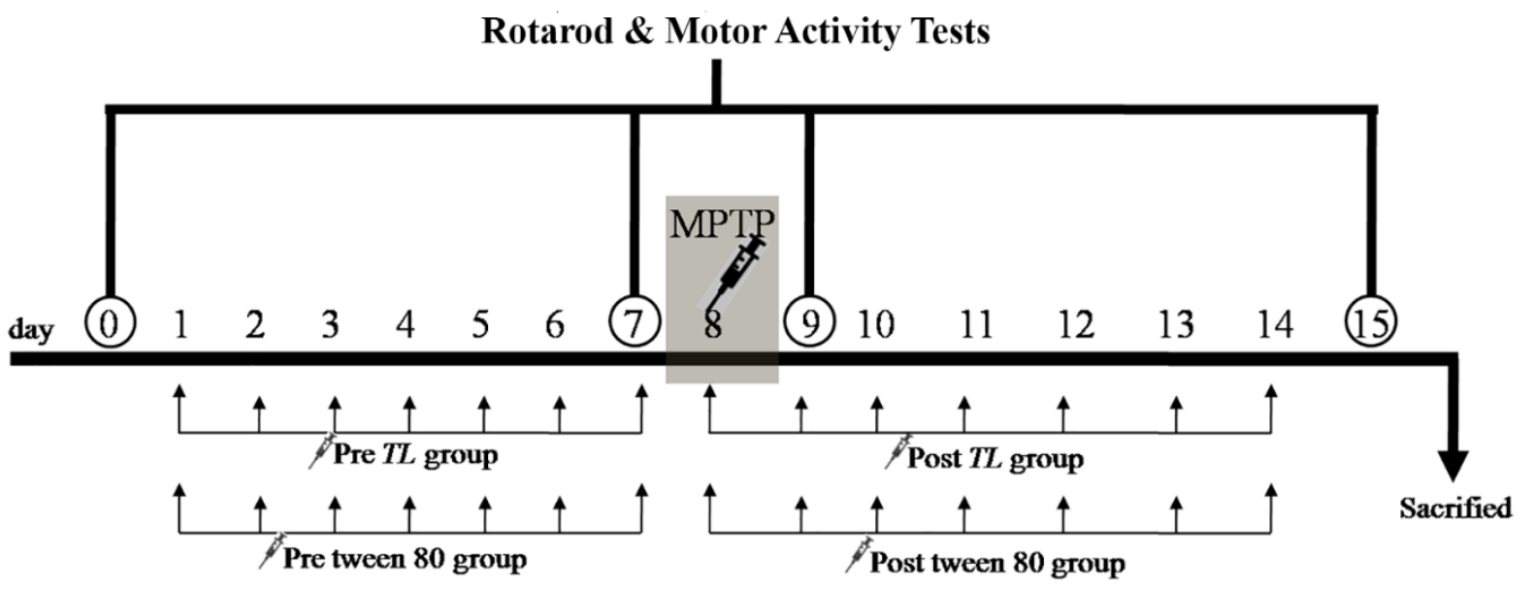

Figure 1. The experimental design shows the pre- and post-treatment strategies. The $T L$ extract or Tween 80 was given to mice for 7 days before and after the MPTP inducing to be PD in the pre-treated and post-treated mouse groups, respectively. The Rotarod and Motor Activity Tests were examined in all groups on day 0, 7, 9 and 15. MPTP; the 1-methyl4-phenyl-1,2,3,6-tetrahydropyridine, TL; Thunbergia laurifolia Lindl.

\section{Behavioral analysis and brain tissue preparation}

Rotarod test. Thirty minutes before the trial, mice of each group were selected, and were also allowed to rest before test. The mice were placed on the rotating bars of a Rotarod unit (7750, UGO BASILE). The rotation speed increased steadily at a rate of $4,12,19,26,33$, and finally 40 rounds per minute. The time that the mice were spent on the rotating bar before falling down was recorded as the latency time in seconds. 
Motor activity test. The motor activity was estimated in an automated frame box ( $25 \times 25 \mathrm{~cm}^{2}$, frame) containing an infrared beam (LE8825, PANLAB). One hour before the trail, the mice of each group were randomly selected and were then allowed to rest before the test. The tested mice were placed in the frame box for 15 minutes. The frequency of mouse movement was detected by beams connected to a monitor analyzer.

\section{Perfusion and sectioning}

Following the 15 day experimental period, the control mice and induced mice were given a lethal dose of ether and were perfused transcardially with the phosphate buffer (PB) solution, followed by a fixative of $4 \%$ paraformaldehyde, $\mathrm{pH}$ 7.4. After the perfusions were performed, the brains were removed from the skulls. Brains were cut into $50 \mu \mathrm{m}$ thick coronal sections using a Vibratome (Leica 1200s). The brain sections were collected from rostral to caudal sections every $5^{\text {th }}$ section in PB.

\section{Immunofluorescence and the labeling of the dopaminergic neurons in SNpc}

To reveal the dopaminergic neurons, one row of brain sections from three mouse brains of each group were processed by immunofluorescence. The sections were incubated in a solution of $3 \%$ hydrogen peroxide $\left(\mathrm{H}_{2} \mathrm{O}_{2}\right)$ in methanol one hour to eliminate any endogenous peroxidase activity. It was then washed 3 times in $0.1 \mathrm{M} \mathrm{PB}$ for 10 minutes. The sections of each group were immersed in blocking buffer containing 10\% normal goat serum (NGS), $0.1 \%$ Triton X-100 in PBS for 60 minutes and then were incubated in a solution containing the mouse monoclonal primary antibody to tyrosine hydroxylase (TH) $(65106 \mathrm{M} 4874 \mathrm{~V}$, Sigma) at a dilution of $1: 1,500$ at $4^{\circ} \mathrm{C}$ overnight. The incubated sections were subsequently rinsed 3 times in $0.1 \mathrm{M}$ PB for 10 minutes and then were placed in a solution containing the goat anti-mouse $\operatorname{IgG}(\mathrm{H}+\mathrm{L})$ secondary antibody, Rhodamine conjugate (Catalog No. 31660, Thermo Fisher) at a dilution of 1:100 for one hour. The sections were then washed in $0.1 \mathrm{M} \mathrm{PB}$ and mounted on a slide. The TH immunoreactive ( $\mathrm{THir}^{+}$) cells in the SNpc of all groups were examined under a fluorescent microscope. The photos of $\mathrm{THir}^{+}$cells in SNpc were taken. THir+ cells were indicated as cells containing TH antigen-antibody complexes conjugated with Rhodamine in cytoplasm and the central dark nuclei. The number of $\mathrm{THir}^{+}$cells in all SNpc sections of each brain were counted using an Image $\mathbf{J}$ program and was presented as mean $\pm \mathrm{SD}$.

\section{Statistical analysis}

All data was presented as mean $\pm \mathrm{SD}$. Differences among means were analyzed using one-way analysis of variance (ANOVA) which was followed by a post-hoc analysis with a Tukey test for multiple comparisons using an $\mathrm{R}$ program. The values of $P<0.05$ were considered statistically significant. 


\section{RESULTS}

\section{Effects of $T L$ extract on MPTP induced the motor co-ordination dysfunction}

The MPTP mouse models of PD demonstrate the motor behavioral defects including co-ordination. The Rotarod test was applied to mice in order to evaluate their co-ordination in terms of time spent running on the rotating rod or any latency time before falling off the rods. As shown in Figure 2, on day 0 and 7, there were no difference of co-ordination functions in all groups. On day 9, the latency times of the all MPTP induced mice had significantly reduced compared to the control $(P<0.01$ for the MPTP + pre $T L$ and $P<0.001$ for the rest $)$. On day 15 , there were significant differences of the latency times of the vehicle groups $(P<0.001)$ and the MPTP + post $T L$ group $(P<0.05)$ compared to the control. The latency time in the MPTP + pre $T L$ had significantly increased on both day 9 $(P<0.001)$ and day $15(P<0.01)$ when compared to the vehicle groups. Therefore, the pre-treatment of $T L$ extract of $200 \mathrm{mg} / \mathrm{kg}$ of BW can improve the coordination of the MPTP induced mice.

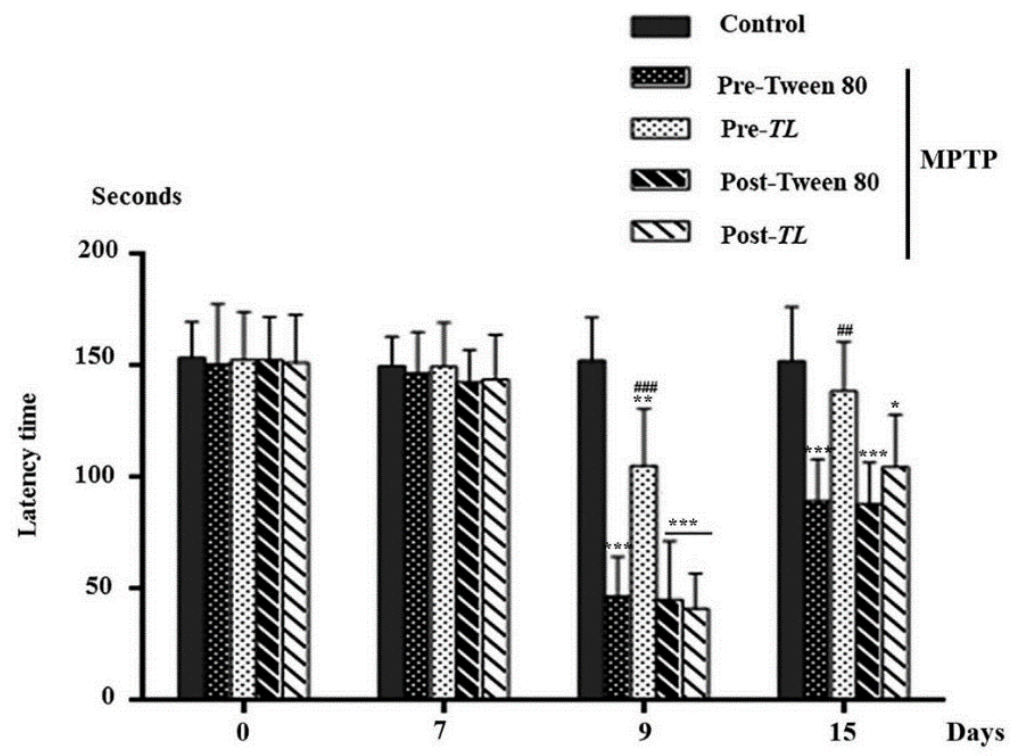

Figure 2. The latency time on the rotating rod of the control, pre Tween 80 , pre $T L$, post Tween 80, and post $T L$ of the MPTP induced mice on day 0 , 7,9 , and 15 . The data of latency time (seconds) were shown as mean \pm $\mathrm{SD} ; \mathrm{n}=6$. $* * * P<0.001, * * P<0.01, * P<0.05$ versus the control and ${ }^{\# \# \#} P<0.001,{ }^{\# \#} P<0.01$ versus the MPTP + pre Tween 80 . 


\section{Effects of $T L$ extract on MPTP induced deficiency in motor activity.}

The frequency of movements was recorded to evaluate the motor activities of all five groups of mice. Similar to their latency time, the motor activities of all mice groups on day 0 and day 7 were not significantly different as shown in Figure 3. The motor activities of the MPTP + pre Tween 80, MPTP + post Tween 80 and MPTP + post $T L$ groups significantly reduced on day $9(P<0.001$ in all groups) and on day 15 ( $P<0.01, P<0.001$, and $P<0.05$, respectively) compared to that of the control. Obviously, the MPTP + pre $T L$ group of mice significantly increased their motor activity on day 9 and day 15 from the pre - vehicle groups. Therefore, the pre $T L$ treatment for the 7 day period before the MPTP inducing in mice can improve their motor movements or bradykinesia of the mouse model of PD.

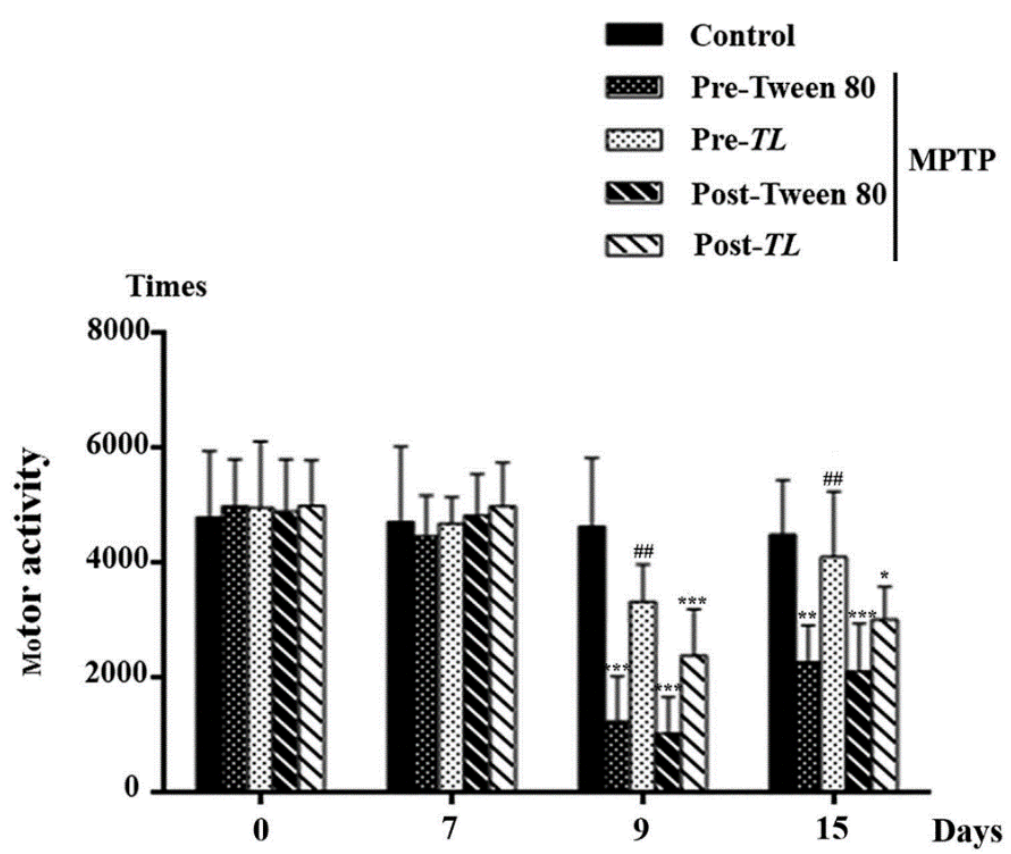

Figure 3. The frequency of movement on Motor Activity Test in 15 minutes of mice in the control, the pre Tween 80 , the pre $T L$, the post Tween 80 , and post $T L$ treatments of the MPTP induced mice on day $0,7,9$, and 15. The data of motor activity (times) is shown as mean \pm SD; $n=6$. *** $P<0.001$, ** $P<0.01, * P<0.05$ vs. the control; ${ }^{\# \#} P<0.01$ vs. the pre Tween $80+$ MPTP.

\section{Effects of $T L$ extract on MPTP induced dopaminergic neuron depletion.}

The dopaminergic neurons in SNpc can be observed by the TH immunoreactive $\left(\mathrm{THir}^{+}\right)$cells. All MPTP induced mice showed dopaminergic neuron depletions as shown in Figure 4 A. The numbers of $\mathrm{THir}^{+}$cells in $\mathrm{SNpc}$ were significantly reduced in all MPTP induced mice when compared to that of the control (Figure 4B). However, that numbers of the pre $T L$ group was less different $(P<0.05)$ than that of the post $T L$ group $(P<0.01)$ when compared to 
that of the control. of Both pre $T L$ and post $T L$ groups demonstrated significant higher numbers of $\mathrm{THir}^{+}$cells than that of their vehicle groups $(P<0.001)$. Therefore, the degeneration of dopaminergic neurons in SNpc was due to the MPTP inducing that may be reversed by treatment with the $T L$ extract.

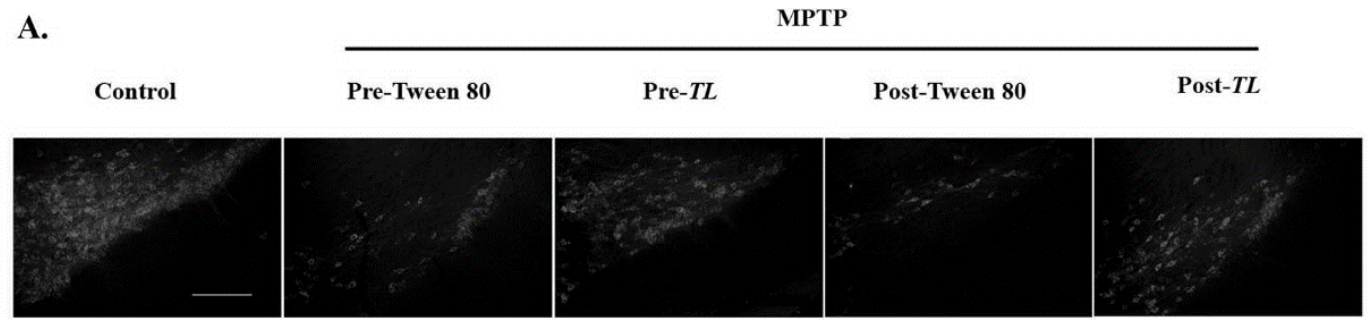

B.

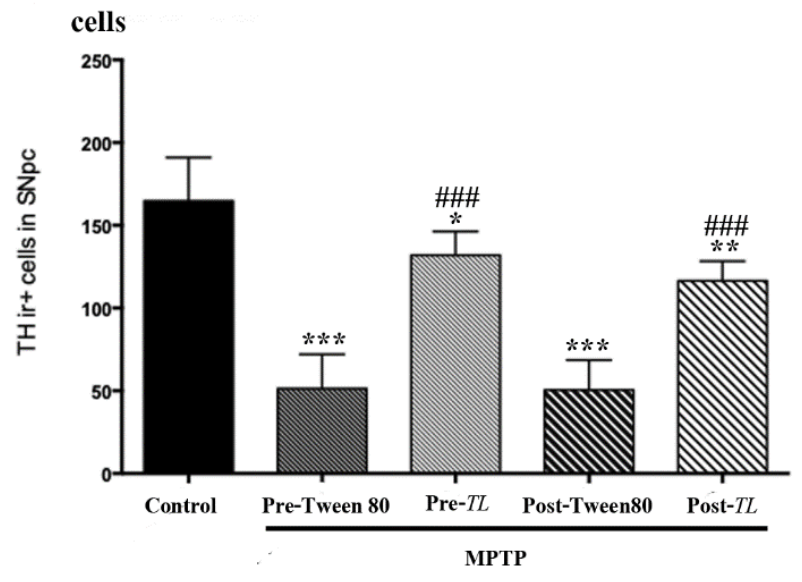

Figure 4. (A) The SNpc sections containing the $\mathrm{THir}^{+}$cells from the control, MPTP + pre Tween 80, MPTP + pre TL, MPTP + post Tween 80, and MPTP + post $T L$ groups are demonstrated. Scale bars $=100 \mu \mathrm{m}$ and was applied in all panels. (B) The data of the $\mathrm{THir}^{+}$cells were shown as mean $\pm \mathrm{SD}, \mathrm{n}=6$. $* * * P<0.001$, $* * P<0.01$, and $* P<0.5$ versus the control. \#\#\# $P<0.001$ versus the vehicle treated group. SNpc; substantia nigra pars compacta, THir ${ }^{+}$: Tyrosine hydroxylase immunoreactive.

\section{DISCUSSION}

This study used male C57BL/6 mice as the acute MPTP induced mouse model of PD as has been done in previous studies (Liu et al., 2014; Guo et al., 2016). The C57BL/6 mice were the mouse strain that is most sensitive to the toxic effects of MPTP compared to others (Muthane et al., 1994; Hamre et al., 1999). The MPTP was also found to be a neurodegenerative toxin in SNpc in humans (Langston et al., 1999). Our acute mouse model of PD received four IP injections of MPTP $20 \mathrm{mg} / \mathrm{kg}$ of body weight at 2 hour intervals. There was an approximately $70-80 \%$ loss of dopaminergic neurons in both MPTP + pre Tween 80 and MPTP + post Tween 80 groups. These were relatively close to the previous 
studies that reported a 60-70\% loss of the nigrostriatal dopaminergic neurons in the acute mouse models of PD (Jakowec et al., 2004).

The anti-oxidant and anti-inflammation properties of $T L$ have been reported (Chan and Lim, 2006; Wonkchalee et al., 2012). Boonyarikpunchai et al. (2014) found high phenolic and flavonoid compound concentrations in the ethanol and water extraction of $T L$. The $T L$ extract used in this study was ethanol extracted $T L$ leaves. The sample of the $T L$ ethanol extract solution contains $106.0 \mathrm{mg} / \mathrm{L}$ anti-oxidant and $290.59 \mu \mathrm{g} / \mathrm{ml}$ phenolic compounds. Thus, the effects of the $T L$ treatment in a PD model used in this study could obtain results concerning their anti-oxidant properties.

This study found that the $T L$ treatment before inducing with MPTP attenuated the motor dysfunction such as coordination and bradykenisia of the MPTP mouse model of PD more than the post $T L$ treatment. These results are similar to a previous study which reported that rats fed with $T L$ extract prior to cadmium explosion demonstrated less motor abnormality than those rats fed with $T L$ extract after the cd explosion (Ruangyuttikarna et al., 2013).

Our results demonstrated that after one week of the MPTP injection, the pre-treatment strategy of $T L$ extract in the acute MPTP significantly improved motor co-ordination and increased motor activity. On the other hand, the post- $T L$ treatment group and the post-vehicle group did not significantly exhibit any motor behavior. This may be due to the fact that pre-treatment with $T L$ extract on the acute MPTP induced mice might reduce the toxicity the MPTP under levels that can cause PD symptoms. Therefore, the motor improvements of MPTP models resulted from the detoxification properties of $T L$ in MPTP toxins. The detoxification of $T L$ was also supported by evidence of reduction of others toxins such as lead (Tangpong and Satarug, 2010), paraquat (Ussanawarong et al., 2000), and cadmium (Ruangyuttikarna et al., 2013).

The leaf $T L$ extract was found to prevent the loss of motor and cognitive performance resulting from lead $(\mathrm{Pb})$ induced neurotoxicity in a dose dependent pattern (Palipoch et al., 2011; Phyu and Tangpong, 2013 ), reducing the death of the hippocampal neurons of rats poisoned by lead (Tangpong and Satarug, 2010). Since our study used the $T L$ extract at dose of $200 \mathrm{mg} / \mathrm{kg} \mathrm{BW}$ to treat the MPTP induced mice PD models, it did not significantly alleviate the dopaminergic degeneration in both the pre- and post treatment strategies. However, the pre-treatment with the $T L$ extract at $200 \mathrm{mg} / \mathrm{BW}$ significantly improved coordination and motor activity in these models. These findings might indicate that $T L$ extract has protective effects on MPTP induced mouse models of PD. However, the reversed motor deficiency effects and the neuroprotective properties of the $T L$ extract in dose dependent manners in the MPTP induced PD models need to be investigated further. 


\section{CONCLUSION}

The $T L$ extract was known for its detoxification and anti-oxidant properties. MPTP is a toxin, which is commonly used to induce PD in a mouse model. PD is caused by dopaminergic neuron degeneration that leads to motor impairments. The pre-treatment of $T L$ extract of $200 \mathrm{mg} / \mathrm{kg}$ in the MPTP mouse PD model reversed motor impairments and increased motor co-ordination and motor activities. However, the post $T L$ treatment did not significantly improve motor deficits. Thus, the pre-treatment of $T L$ extract of $200 \mathrm{mg} / \mathrm{kg}$ on MPTP for 7 days can prevent motor deficiency in the MPTP induced mouse PD model.

\section{ACKNOWLEDGMENTS}

This study was supported by the Faculty of Medicine Research Fund, grant no. 050-2561, Chiang Mai University, Chiang Mai, Thailand.

\section{REFERENCES}

Alam, G., Edler, M., Burchfield, S., and Richardson, J.R. 2017. Single low doses of MPTP decrease tyrosine hydroxylase expression in the absence of overt neuron loss. Neurotoxicology. 60: 99-106. https://doi.org/10.1016/j.neuro. 2017.03.008

Blandini, F., and Armentero, M.T. 2012. Animal models of Parkinson's disease. The FEBS Journal. 279(7): 1156-1166. https://doi.org/10.1111/j.17424658.2012.08491.x

Boonyarikpunchai, W., Sukrong, S., and Towiwat, P. 2014. Anti-nociceptive and anti-inflammatory effects of rosmarinic acid isolated from Thunbergia laurifolia Lindl. Pharmacology, Biochemistry, and Behavior. 124: 67-73. https://doi.org/10.1016/j.pbb.2014.05.004

Chan, E.W.C., Eng, S.Y., Tan, Y.P., and Wong, Z.C. 2011. Phytochemistry and pharmacological properties of Thunbergia laurifolia: a Review. Pharmacognosy Journal. 3(24): 1-6. https://doi.org/10.5530/pj.2011.24.1

Chan, E.W.C., and Lim, Y.Y. 2006. Anti-ooxidant Activity of Thunbergia laurifolia tea. Journal of Tropical Forest Science. 18(2): 130-136.

Guo, Z., Xu, S., Du, N., Liu, J., Huang, Y., and Han, M. 2016. Neuroprotective effects of stemazole in the MPTP-induced acute model of Parkinson's disease: involvement of the dopamine system. Neuroscience Letters. 616: 152-159. https://doi.org/10.1016/j.neulet.2016.01.048

Hamre, K., Tharp, R., Poon, K., Xiong, X., and Smeyne, R.J. 1999. Differential strain susceptibility following 1-methyl-4-phenyl-1,2,3,6-tetrahydropyridine (MPTP) administration acts in an autosomal dominant fashion: quantitative analysis in seven strains of Mus musculus. Brain Research. 828(1-2): 91103. https://doi.org/10.1016/s0006-8993(99)01273-1 
Hutter-Saunders, J.A.L., Gendelman, H.E., and Mosley, R.L. 2012. Murine motor and behavior functional evaluations for acute 1-methyl-4-phenyl-1,2,3,6tetrahydropyridine (MPTP) intoxication. Journal of Neuroimmune Pharmacology. 7(1): 279-288. https://doi.org/10.1007/s11481-011-9269-4

Jackson-Lewis, V., and Przedborski, S. 2007. Protocol for the MPTP mouse model of Parkinson's disease. Nature Protocols. 2(1): 141-151. https://doi.org/10.1038/nprot.2006.342

Jankovic, J. 2008. Parkinson's disease: clinical features and diagnosis. Journal of Neurology, Neurosurgery, and Psychiatry. 79(4): 368-376. https:// doi.org/10.1136/jnnp.2007.131045

Jakowec, M.W., Nixon, K., Hogg, E., McNeill, T., and Petzinger, G.M. 2004. Tyrosine hydroxylase and dopamine transporter expression following 1-methyl-4-phenyl-1,2,3,6-tetrahydropyridine-induced neurodegeneration of the mouse nigrostriatal pathway. Journal of Neuroscience Research. 76(4): 539-550. https://doi.org/10.1002/jnr.20114

Junsi, M., and Siripongvutikorn, S. 2016. Thunbergia laurifolia, a traditional herbal tea of Thailand: botanical, chemical composition, biological properties and processing influence. International Food Research Journal. 23: 923-7.

Kasahara, J., Choudhury, M.E., Yokoyama, H., Kadoguchi, N., and Nomoto, M. 2013. Chapter 26 - Neurotoxin 1-methyl-4-phenyl-1,2,3,6tetrahydropyridine-induced animal models for Parkinson's disease A2 Conn, P. Michael. Animal Models for the Study of Human Disease. Boston: Academic Press. p. 633-50.

Kozina, E.A., Khakimova, G.R., Khaindrava, V.G., Kucheryanu, V.G., Vorobyeva, N.E., Krasnov, A.N., Georgieva, S.G., Kerkeian-Le Goff, L. and Ugrumov, M.V. 2014. Tyrosine hydroxylase expression and activity in nigrostriatal dopaminergic neurons of MPTP-treated mice at the presymptomatic and symptomatic stages of parkinsonism. Journal of Neurological Sciences. 340(1-2): 198-207. https://doi.org/10.1016/j.jns. 2014.03.028

Langston, J.W., Forno, L.S., Tetrud, J., Reeves, A.G., Kaplan, J.A., and Karluk, D. 1999. Evidence of active nerve cell degeneration in the substantia nigra of humans years after 1-methyl-4-phenyl-1,2,3,6tetrahydropyridine exposure. Annals of Neurology. 46(4): 598-605. https://doi.org/10.1002/1531-8249(199910)46:<598::AID-ANA7>3.0.C0; 2-F

Lee, Y., Heo, G., Lee, K.M., Kim, A.H., Chung, K.W., Im, E., Chung, H.Y., and Lee, J. 2017. Neuroprotective effects of 2, 4-dinitrophenol in an acute model of Parkinson's disease. Brain Research. 1663: 184-193. 
Liu, J., Gao, J., Tu, S., Xu, S., Liu, Y., Shang, W., Gu, C., Huang, Y., and Han, M. 2014. Neuroprotective effects of Jitai tablet, a traditional Chinese medicine, on the MPTP-induced acute model of Parkinson's disease: involvement of the dopamine system. Evidence-based Complementary and Alternative Medicine. 2014: Article ID 542383. https://doi.org/10.1155/ 2014/542383

Moraes, L.S., Rohor, B.Z., Areal, L.B., Pereira, E.V., Santos, A.M.C., Facundo, V.A., Santos, A.R.S., Pires, R.G.W., and Martins-Silva, C. 2016. Medicinal plant Combretum leprosum mart ameliorates motor, biochemical and molecular alterations in a Parkinson's disease model induced by MPTP. Journal of Ethnopharmacology.185: 68-76. https://doi.org/10.1016/j.jep.2016.03.041

Mu, X., He, G.R., Yuan, X., Li, X.X., and Du, G.H. 2011. Baicalein protects the brain against neuron impairments induced by MPTP in C57BL/6 mice. Pharmacology, Biochemistry, and Behavior. 98(2): 286-291. https://doi. org/10.1016/j.pbb.2011.01.011

Muthane, U., Ramsay, K.A., Jiang, H., Jackson-Lewis, V., Donaldson, D., Fernando, S., Ferreira, M., and Przedborski, S. 1994. Differences in nigral neuron number and sensitivity to 1-methyl-4-phenyl-1,2,3,6tetrahydropyridine in C57/bl and CD-1 mice. Experimental Neurology. 126(2): 195-204. https://doi.org/101006/exnr.1994.1058

Pain, S., Gochard, A., Bodard, S., Gulhan, Z., Prunier-Aesch, C., and Chalon, S. 2013. Toxicity of MPTP on neurotransmission in three mouse models of Parkinson's disease. Experimental and Toxicologic Pathology : 65(5): 689694. https://doi.org/10.1016/j.etp.2012.09.001

Palipoch, S., Jiraungkoorskul, W., Tansatit, T., Preyavichyapugdee, N., and Kosai, P. 2011. Protective efficiency of Thunbergia laurifolia leaf extract against lead (II) nitrate-induced toxicity in Oreochromis niloticus. Journal of Medicinal Plants Research. 5(5): 719-728.

Philippens, IH., 't Hart, B.A., and Torres, G. 2010. The MPTP marmoset model of parkinsonism: a multi-purpose non-human primate model for neurodegenerative diseases. Drug Discovery Today. 15(23-24): 985-990. https://doi.org/10.1016/J.drudis.2010.08.009

Phyu, M.P., and Tangpong, J. 2013. Protective effect of Thunbergia laurifolia (Linn.) on lead induced acetylcholinesterase dysfunction and cognitive impairment in mice. BioMed Research International. 2013: 186098. https://doi.org/101155/2013/186098

Ruangyuttikarna, W., Chattaviriyaa, P., Morkmeka, N., Chuncharuneeb, S., and Lertprasertsukec, N. 2013. Thunbergia laurifolia leaf extract mitigates cadmium toxicity in rats. ScienceAsia. 39: 19-25. https://doi.org/10.2306/ scienceasia1513-1874.2013.39.019 
Tangpong, J., and Satarug, S. 2010. Alleviation of lead poisoning in the brain with aqueous leaf extract of the Thunbergia laurifolia (Linn.). Toxicology letters. 198(1): 83-88. https://doi.org/10.1016/j.toxlet.2010.04.031

Thongsaard, W., and Marsden, C. 2013. Effect of Thunbergia laurifolia extract on extracellular dopamine level in rat nucleus accumbens. Journal of the Medical Association of Thailand. 96 Suppl 1: S85-S89.

Tieu, K.A. 2011. Guide to neurotoxic animal models of Parkinson's disease. Cold Spring Harbor Perspectives in Medicine: 1(1): a009316. https:// doi.org/10.1101/cshperspect.a009316

Ussanawarong, S., Mahakunakorn, P., Tessiri, T., and Porasupattana, S. 2000. Effect of Thunbergia laurifolia Linn on detoxication of pesticide poisoning (paraquat). KKU Research Journal. 5: 11-17.

Wonkchalee, O., Boonmars, T., Aromdee, C., Laummaunwai, P., Khunkitti, W., Vaeteewoottacharn, K., Sriraj, P., Aukkanimart, R., Loilome, W., and Chamgramol, Y. 2012. Anti-inflammatory, antioxidant and hepatoprotective effects of Thunbergia laurifolia Linn. on experimental opisthorchiasis. Parasitology Research. 111(1): 353-359. https://doi.org/10.1007/s00436012-2846-5 